\title{
Effects of Adding Carbon Sources and Nutrient Salts on the Acidification and Microbial Community Structure of Coal Gangue
}

\section{Qi Zhu}

Chinese Research Academy of Environmental Sciences

\section{Mengying Ruan}

China University of Mining and Technology Beijing Campus

Zhenqi Hu ( $\nabla$ huzq@cumtb.edu.cn )

China University of Mining and Technology - Beijing Campus

Chun Ye

Chinese Research Academy of Environmental Sciences

\section{Research Article}

Keywords: coal gangue, microbial community, carbon source, microbial remediation, acid pollution

Posted Date: November 16th, 2021

DOI: https://doi.org/10.21203/rs.3.rs-1014436/v1

License: (c) (i) This work is licensed under a Creative Commons Attribution 4.0 International License. Read Full License 


\section{Abstract}

Acidic pollution from gangue oxidation has become a primary environmental problem in coal mining areas in China. The use of microorganisms to remediate acidic pollution in coal gangue piles has been indicated to be effective, but environmental differences and carbon sources in different mining areas have become important factors restricting microbial activity. Instead of the addition of new functional bacteria to gangue piles, carbon sources and nutrient salts were added to recently discharged gangue to enhance the activity of beneficial bacteria in the indigenous microbial community. The changes in $\mathrm{pH}$ and electrical conductivity $(\mathrm{EC})$ of the gangue leachate as well as the composition and abundance of the functional microbial community on the surface of the gangue were analyzed by leaching simulation experiments and 16S rRNA sequencing. The results showed that (1) the addition of a carbon source maintained the $\mathrm{pH}$ of the gangue leachate at 6.31 6.65, which was significantly higher than that of the control group, but the $\mathrm{pH}$ of the leachate decreased significantly after the addition of the carbon source was stopped. (2) The addition of carbon sources and nutrient salts changed the microbial community composition on the surface of the gangue, and the species diversity index decreased. The dominant genera in the experimental group were Listeria, Arthrobacter, and Enterococcus; Thiobacillus was not the dominant genus in any of the treatments. (3) The functional gene types in the experimental and control groups were almost the same, but their relative abundance changed. The abundance of functional genes related to the sulfur cycle increased substantially in the experimental group, and the abundance of genes involved in the nitrogen and carbon cycles also increased, albeit to different degrees.

\section{Introduction}

Coal gangue accounts for approximately $10 \%$ 30\% of raw coal production and is solid waste generated during coal mining, washing, and processing (Hu et al.,2005). Acidification of coal gangue during storage releases many poisonous and harmful gases such as $\mathrm{H}_{2} \mathrm{~S}, \mathrm{CO}$, and $\mathrm{SO}_{2}$ and produces acid mine drainage (AMD), which consists of high concentrations of sulfate and heavy metal ions (Akcil, Koldas,2006; Baker, Banfield,2003). The Environmental Protection Agency (EPA) has reported that the environmental risk of AMD is second only to global warming and ozone depletion (Acharya \& Kharel, 2020; Chen et al., 2021; Naidu et al., 2019). According to incomplete statistics, the cumulative coal gangue stockpile in China is approximately 4.6 billion tons, occupying more than 12,000 hectares of land, and continues to increase at an annual rate of 160 million tons, making it the largest industrial solid waste in China (Zhu et al.,2020). Almost all of the world's major coal-producing countries, such as the United States, Germany, South Africa, and Canada, have serious AMD pollution problems (Geldenhuis \& Bell, 1998; Knöller et al.,2004; Jacobs et al.,2014), with AMD-polluted rivers exceeding $20000 \mathrm{~km}$ in the United States (Skousen et al., 2019). AMD is characterized by extreme acidity and high sulfate and heavy metal contents, which can corrode infrastructure, pollute water sources, harm aquatic life, and enter the food chain, threatening human health (Adil \& Tang 2018; Senoro et al. 2021; Wang et al. 2021).

Studies have shown that chemoautotrophic oxidizing bacteria such as Thiobacillus ferrooxidans (Aller et al. 2001; Leathen et al., 1953) and Thiobacillus thiooxidans (Egiebor \& Oni, 2007) can accelerate the 
acidification of coal gangue through biocatalysis, and an acidic environment is more conducive to the proliferation of acidophilic oxidizing bacteria, thus forming a spontaneous cyclic reaction. The use of sulfate-reducing bacteria (SRB) to treat acidified pollution in mine waste rock dumps is one of the most promising methods currently used internationally. Phyo et al. (2020) and Jing et al. (2017) studied the competitive growth of SRB and iron-reducing bacteria with indigenous autotrophic acidophilic bacteria under different conditions and proposed that the growth capacity of SRB and iron-reducing bacteria under anaerobic acid conditions was significantly higher than that of other bacteria; thus, SRB and iron-reducing bacteria could be used to inhibit pyrite oxidation in situ and achieve acid suppression effects. Hu et al. (2009) were the first to suggest that SRB could be applied to the in situ treatment of acid pollution in coal gangue piles. Zhu et al. (2020) isolated a T. ferrooxidans strain with facultative anaerobic properties from coal gangue samples in Shanxi, China, and demonstrated via column leaching simulation experiments that the strain could effectively increase the $\mathrm{pH}$ and remove sulfate from coal gangue leachates. In addition, Tang et al. (2014) isolated a strain of SRB that increased the $\mathrm{pH}$ of coal gangue leachate from 4 to 6.5 within $2 \mathrm{~d}$ from coal mine soil in Hunan Province.

Currently, studies on sulfate-reducing bacterial remediation of acidified coal gangue pollution have generally adopted the experimental method by which SRB are added to coal gangue (Hu et al.,2009; Kim et al.,1999; Tang et al., 2014). However, SRB are very widely distributed in nature, and the native bacterial community of coal gangue piles usually contains SRB (Barton \& Fauque, 2009); however, their relative abundance is low, and artificial addition of SRB to coal gangue piles is not necessary. SRB are heterotrophic; however, most of the oxidizing bacteria catalyzing the oxidation of coal gangue are autotrophic bacteria, so the dominance of SRB in the bacterial community can be improved by adding carbon sources and nutrient salts that promote microbial growth to help alleviate the acidic mine wastewater produced by acidification of coal gangue (Tuttle et al.,1969). Bozau et al. (2006) added rice straw and $\mathrm{CaCO}_{3}$ to acidic mine lakes to enhance the activity of SRB and their ability to solidify heavy metals and ultimately achieved successful remediation of acidic wastewater. Jin et al. (2008) proposed that dairy waste could be used as a carbon source to accelerate the growth of SRB through the addition of carbon sources to achieve control of AMD sources; their field study at a reclaimed coal mine in central Tennessee, USA, successfully raised the $\mathrm{pH}$ of mine water from 5.7 to 7.3 , with an $84 \%$ reduction in iron concentration and a $108 \mathrm{mg} / \mathrm{L}$ reduction in sulfate concentration. Sand et al. (2007) covered acidic mining waste rock using crushed limestone and organic material consisting of a mixture of topsoil, fermented pig manure, and sawdust (2:1:1 by volume) and found a $90 \%$ reduction in iron and a $40 \%$ reduction in sulfate content in the leachate. $\mathrm{Ma}$ and $\mathrm{Hu}$ (2014) found that the $\mathrm{pH}$ of leachate increased from 2.0 to 7.5 and that the EC decreased to less than $2000 \mu \mathrm{S} \cdot \mathrm{cm}^{-1}$ when coal gangue was covered with $5 \mathrm{~cm}$ of sludge from a sewage treatment plant. Therefore, when additional carbon sources are provided, the dominance of heterotrophic microorganisms can be effectively increased, and the microbial community composition of coal gangue mountains can be improved, thus reducing the acid pollution of coal gangue.

In this study, a leaching simulation experiment was used to add sodium lactate and inorganic salt to the new coal gangue, and the $\mathrm{pH}$ and $\mathrm{EC}$ changes in the leachate were measured. 16S rRNA high-throughput sequencing was used to analyze the microbial community composition and functional diversity on the 
surface of the coal gangue. By studying the effects of carbon source and nutrient salt addition on the acid pollution and microbial community composition of coal gangue, we aimed to explore the effect and mechanism of controlling acidification of coal gangue by stimulating sulfate-reducing bacterial activity, reveal the interaction between microorganisms and environmental acidity at the initial stage of coal gangue storage, and provide a theoretical basis and data support for in situ remediation of acid pollution of coal gangue piles based on microbial methods.

\section{Materials And Methods \\ 2.1 Experimental samples}

The coal gangue samples used in the experiment were collected from a coal preparation plant of a coal mine in Taiyuan, Shanxi Province, China. The sampling site is located at 112.16' E and 37.92' N. The main chemical element compositions of the coal gangue samples are shown in Table 1.

Table 1

Main components of the coal gangue samples

\begin{tabular}{|lllllllllllll|}
\hline Element & Mn & Co & Ni & C & O & F & Mg & Al & Si & K & Ca & Fe \\
\hline $\begin{array}{l}\text { Content } \\
(\%)\end{array}$ & 0.07 & 0.04 & 0.04 & 7.17 & 55.88 & 0 & 0.27 & 15.68 & 18.34 & 1.49 & 0.35 & 0.66 \\
\hline
\end{tabular}

\subsection{Experimental methods}

The experimental method is shown in Fig. 1. After crushing the newly produced coal gangue, coal gangue particles with particle sizes of 2 5 mm were selected through an analysis sieve. Twelve pots were used, which were divided into four groups: Tx-1, Tx-2, Tx-3, and Tx-4. One piece of qualitative filter paper and 350 $\mathrm{g}$ of coal gangue particles were placed in each pot. A $100 \mathrm{ml}$ solution of carbon source (sodium lactate) and nutrient solution $\left(\mathrm{KH}_{2} \mathrm{PO} 4,0.5 \mathrm{~g} ; \mathrm{NH}_{4} \mathrm{Cl}, 1.0 \mathrm{~g} ; \mathrm{Na}_{2} \mathrm{SO}_{4}, 1.0 \mathrm{~g} ; \mathrm{CaCl}_{2}, 0.05 \mathrm{~g} ; \mathrm{MgCl} 6 \mathrm{H}_{2} \mathrm{O}, 2.0 \mathrm{~g}\right.$; deionized water, $1000 \mathrm{ml}$ ) was added according to the formula in Table 2 at $0 \mathrm{~d}$ and $7 \mathrm{~d}$. Tx-4 was used as a control treatment, and $100 \mathrm{ml}$ of deionized water was added as a substitute. All the pots were subjected to $28^{\circ} \mathrm{C}$. After the experiment started, $100 \mathrm{ml}$ of deionized water was added to each pot every 7 days, and a $500 \mathrm{ml}$ beaker was used to collect coal gangue leachates. The $\mathrm{pH}$ and $\mathrm{EC}$ of the solutions were measured by a $\mathrm{pH} / \mathrm{EC}$ meter (coupled pH and EC meters, DZS-708L, INESA Scientific Instrument Co., Ltd.). On the 28th day of the experiment, $10.0 \mathrm{~g}$ of solid coal gangue samples was collected from each treated pot for $16 \mathrm{~S}$ rRNA high-throughput sequencing. 
Table 2

Composition of additives in the different treatments

\begin{tabular}{|c|c|c|}
\hline Treatment & 0-7 d Additives & 7 14 d Additives \\
\hline$T x-1$ & $\begin{array}{l}100 \mathrm{ml} \text { of a } 20 \% \text { nutrient solution, } \\
0.02 \mathrm{~g} \text { of sodium lactate }\end{array}$ & $\begin{array}{l}100 \mathrm{ml} \text { of a nutrient salt solution, } \\
0.1 \mathrm{~g} \text { of sodium lactate }\end{array}$ \\
\hline Tx-2 & $\begin{array}{l}100 \mathrm{ml} \text { of a } 20 \% \text { nutrient solution, } \\
0.02 \mathrm{~g} \text { of sodium lactate }\end{array}$ & $\begin{array}{l}100 \mathrm{ml} \text { of a } 50 \% \text { nutrient salt solution, } \\
0.05 \mathrm{~g} \text { of sodium lactate }\end{array}$ \\
\hline$T x-3$ & $\begin{array}{l}100 \mathrm{ml} \text { of a } 20 \% \text { nutrient solution, } \\
0.02 \mathrm{~g} \text { of sodium lactate }\end{array}$ & $0.1 \mathrm{~g}$ of sodium lactate \\
\hline$T x-4$ & Deionized water & Deionized water \\
\hline
\end{tabular}

\subsection{Data analysis}

The PE reads obtained by sequencing were spliced according to their overlapping relationship. After distinguishing samples, the sequences were subjected to quality control measures and filtered, and then OTU cluster analysis and species taxonomy analysis were performed. Based on the results of the OTU clustering analysis, multiple diversity indices for the OTUs were analyzed, and based on the taxonomic information, statistical analysis of community structure was carried out at each classification level. According to the results of the above analyses, a series of in-depth statistical and visual analyses such as beta diversity analysis, grouping test analysis, significant difference testing, correlation analysis of environmental factors, correlation and model prediction analysis, and functional prediction were conducted on the community composition and phylogenetic information of multiple samples.

\section{Results And Discussion}

\subsection{Effects of Carbon Sources and Nutrients on the Acidification of Coal Gangue}

As shown in Figure 2, the $\mathrm{pH}$ of the control group and treatment groups showed a downward trend within $35 \mathrm{~d}$ after the start of the experiment, indicating that the coal gangue exhibited different degrees of acidification. Among the groups, the $\mathrm{pH}$ of the $\mathrm{CK}$ treatment decreased significantly from 6.03 to 4.37 from 0-7 $\mathrm{d}$, while the $\mathrm{pH}$ of all the treatment groups increased slightly and was significantly higher than that of the control group. The $\mathrm{pH}$ of the control group and the treatment groups decreased from 14-21 d, with a greater decrease in $\mathrm{pH}$ in the treatment groups. The $\mathrm{pH}$ of each treatment group was still higher than that of the control group after $14 \mathrm{~d}$, but the difference was not significant. This may be due to the depletion of exogenous nutrients added to the gangue, resulting in a decrease in heterotrophic microbial activity. By comparing the $\mathrm{T} 1, \mathrm{~T} 2$, and $\mathrm{T} 3$ treatments, we concluded that further addition of inorganic salt and changes to the concentration of additives does not significantly alter the $\mathrm{pH}$ of the coal gangue leachate. 
Conductivity EC is commonly used to characterize the soluble salt content in solutions. Figure 3 shows the changes in conductivity for the different treatments within 0-35 $\mathrm{d}$ after the beginning of the experiment. The EC of all the treatment groups increased to varying degrees due to the addition of exogenous substances at the beginning of the experiment. During the experiment, the EC of the leachate of the control group remained essentially stable, while the EC of the treatment groups first increased and then decreased with time. The EC of the T1 treatment decreased from $1078 \mu \mathrm{S} \cdot \mathrm{cm}^{-1}$ to $663 \mu \mathrm{S} \cdot \mathrm{cm}^{-1}$ and then increased to 1232 . After $28 \mathrm{~d}$, the EC of the T1 treatment group was significantly higher than that of the control group and other treatment groups. The minimum EC values of the T2 and T3 treatments were 365 and 412 , respectively, which occurred at $28 \mathrm{~d}$. These results showed that the addition of carbon sources and inorganic salt did not significantly increase the soluble salt content of the leachate of coal gangue, while the addition of a carbon source (sodium lactate) alone led to a significant increase in the EC of the leachate, which may be due to the change in microbial community composition on the surface of the coal gangue.

\subsection{Effects of adding carbon sources and nutrient salts on bacterial species diversity in coal gangue}

The microbial diversity index of each treatment is shown in Table 3. In ecology, the Chao index and Ace index are commonly used to estimate the total number of species. The four treatments had the same relationship according to both the Chao index and the Ace index, and the order from high to low was Tx4 > Tx3 > Tx1 > Tx2. The Shannon index and Simpson diversity index are commonly used to reflect the alpha diversity index. The alpha diversity index of the control group (Tx4) was the highest, followed by those of Tx3, Tx1, and Tx2. The Shannon evenness index reflects the distribution uniformity of the individual number of species in a community. The experimental data showed that the distribution uniformity of all the treatment groups was lower than that of the control group (Tx4), indicating that the number of dominant species in the treatment groups increased and constituted higher proportion in the community.

The experimental results show that the addition of exogenous nutrients reduces the microbial diversity in coal gangue, causing the colony structure to tend to be individualized and further increasing the dominance of the dominant bacteria, which is consistent with the finding of Marris's study that the application of biochar reduces the diversity of soil microorganisms (Marris, 2006). Su et al. (2020) suggested that the addition of a carbon source may affect the activities and metabolic mechanisms of some functional microorganisms in the soil, thus altering the distribution of organic carbon in the soil carbon pool and ultimately leading to a decrease in both soil bacterial community diversity and species abundance. 
Table 3

Alpha diversity index statistics

\begin{tabular}{|llllll|}
\hline Sample & Chao & Ace & Shannon & Shannon evenness & Simpson \\
\hline Tx-1 & 468.00 & 466.23 & 4.34 & 0.71 & 0.06 \\
\hline Tx-2 & 313.00 & 312.26 & 3.95 & 0.69 & 0.07 \\
\hline Tx-3 & 603.43 & 588.64 & 4.38 & 0.69 & 0.05 \\
\hline Tx-4 & 764.49 & 758.69 & 5.13 & 0.78 & 0.01 \\
\hline
\end{tabular}

\subsection{Effects of adding carbon sources and nutrient salts on the bacterial community structure in coal} gangue

More than 1200 bacterial genera were identified in coal gangue samples through high-throughput sequencing analysis. The collinearity of the main phyla with relative abundance in the top 10 is shown in Fig. 4. The common dominant phyla in the treatment groups and the control group were Proteobacteria (38.53\%-53.45\%), Actinobacteria (11.43\%-17.10\%), and Bacteroidetes (1.94\%-7.01\%), which constituted $54 \%-72 \%$ of the bacterial species in the samples. Firmicutes in the treatment group was relatively predominant, with a relative abundance of more than $30 \%$, while the relative abundance of Firmicutes in the control group was only 3.8\%. The abundance of Acidobacteria and Gemmatimonadetes was higher in the control group (at $4.0 \%$ and $4.4 \%$, respectively), while the abundance of these two types of bacteria in the treatment groups was lower than $1 \%$. Studies have shown that $\mathrm{pH}$, nitrate-nitrogen, and organic carbon are important factors affecting the abundance and distribution of Proteobacteria and Acidobacteria (Yao et al.,2016; Zhou et al.,2020).

The distribution of the main genera in the treatment groups and the control group is shown in Figure 5. Arthrobacter, Enterococcus, Acinetobacter and Methylobacterium were the main dominant genera in the treatment groups, and the abundance of these genera increased in response to the addition of carbon sources. Arthrobacter is considered to degrade organic pollutants and adsorb heavy metals (Prasad et al., 2013; Sebai et al., 2011; Ye et al., 2014), and a variety of Arthrobacterstrains that can grow with organic pollutants as carbon sources and energy sources have been isolated thus far (Arora \& Jain, 2011; Cai et al., 2011; Wang et al., 2015). Enterococcus is considered to play an important role in the nitrogen and phosphorus cycles of ecosystems and can better adapt to coal gangue reclamation soil, with a higher relative abundance in reclaimed soil than in natural soil (Hou et al., 2017; Li et al., 2018).

Methylobacterium is the main flora of the aerobic methane-oxidizing bacterial community. The input of inorganic nitrogen promoted the growth rate and relative abundance of Methylobacterium in the soil, which may be because it does not have the ability to fix nitrogen but relies only on the physiological characteristics of exogenous nitrogen to obtain nutrients.

In addition, the addition of $\mathrm{OM}$ and inorganic salt also increased the relative abundance of Listeria, which may be worth noting. Listeria is a common saprophytic bacterium in the soil that exists in various types of environments, and Listeria monocytogenes can cause foodborne diseases. The distribution of Listeria is 
regulated mainly by soil moisture, molybdenum concentrations, and salt concentrations (Liao et al., 2021). Yoon et al. (2021) reported that an increase in the richness and diversity of the soil bacterial community structure is beneficial in inhibiting the proliferation of Listeria.

The main members of the control group were Sphingomonas and Gemmatimonas, which are also involved in nitrogen and phosphorus cycling and improve soil physical and chemical properties (CheeSanford et al., 2019; Song et al.,2021). The abundance of these genera in the treatment groups was significantly reduced, which may be due to competition between bacterial communities. It is worth noting that Thiobacillus was not the dominant genus in the treatment groups or in the control group, indicating that Thiobacillus was not the main influencing factor of the oxidation or acid production in coal gangue in the early storage period of new coal gangue.

\subsection{Effects of carbon source and nutrient addition on bacterial community function}

The functions of the microbial community were predicted by the FAPROTAX database, focusing on the cycling functions of sulfur, carbon, hydrogen, and nitrogen. Different microbial functions and their corresponding abundance are shown in Table 4 (microbial functions with an abundance of 0 or that did not differ were removed).

The experimental group had stronger nitrification and denitrification, which could accelerate the nitrogen cycling rate. The low abundance of nitrogen-fixing microorganisms in the experimental group may be due to the addition of nitrogen, which reduced the dependence of microorganisms on nitrogen fixation. Moreover, the numbers of microorganisms involved in the sulfur cycle were increased in the experimental groups, which indicated that the addition of carbon sources and sulfate could increase the abundance of sulfur-metabolizing functional bacteria in microbial communities and that sulfate addition that continued after 7 days would not affect the sulfate respiration ability of microbial communities. The addition of carbon sources and nutrients enhanced the utilization of methyl compounds, aromatic compounds, and aliphatic compounds in microbial communities and reduced the degradation ability of chitin and hydrocarbons, which was mainly caused by changes in the main electron donors of microorganisms. In addition, almost no bacteria with iron respiratory function were found in any of the treatments, which was consistent with the bacterial community composition analysis results. 
Table 4

Predicted functions of flora according to the FAPROTAX database

\begin{tabular}{|c|c|c|c|c|c|}
\hline Group & & $T x-1$ & Tx-2 & Tx-3 & $T x-4$ \\
\hline \multirow{7}{*}{$\begin{array}{l}\text { Nitrogen } \\
\text { cycle }\end{array}$} & Nitrogen respiration & 700 & 458 & 675 & 503 \\
\hline & Aerobic ammonia oxidation & 330 & 251 & 162 & 77 \\
\hline & Nitrification & 330 & 264 & 198 & 87 \\
\hline & Denitrification & 215 & 313 & 398 & 11 \\
\hline & Nitrogen fixation & 217 & 230 & 270 & 423 \\
\hline & Nitrite respiration & 249 & 313 & 415 & 11 \\
\hline & Ureolysis & 3589 & 2715 & 1385 & 867 \\
\hline \multirow{7}{*}{$\begin{array}{l}\text { Sulfur } \\
\text { cycle }\end{array}$} & Sulfate respiration & 72 & 119 & 96 & 0 \\
\hline & Sulfur respiration & 0 & 0 & 33 & 0 \\
\hline & Thiosulfate respiration & 0 & 0 & 12 & 0 \\
\hline & Respiration of sulfur compounds & 72 & 119 & 141 & 0 \\
\hline & Dark sulfide oxidation & 282 & 646 & 540 & 97 \\
\hline & Dark thiosulfate oxidation & 49 & 0 & 0 & 5 \\
\hline & Dark oxidation of sulfur compounds & 445 & 1156 & 1006 & 112 \\
\hline \multirow{9}{*}{$\begin{array}{l}\text { Carbon } \\
\text { cycle }\end{array}$} & Methanol oxidation & 3572 & 2973 & 2084 & 25 \\
\hline & Methylotrophy & 3572 & 3038 & 2084 & 71 \\
\hline & Chitinolysis & 684 & 120 & 168 & 1940 \\
\hline & Fermentation & 20069 & 24740 & 20116 & 389 \\
\hline & Aromatic compound degradation & 3322 & 4582 & 3756 & 811 \\
\hline & Aliphatic nonmethane hydrocarbon degradation & 144 & 98 & 240 & 14 \\
\hline & Hydrocarbon degradation & 289 & 184 & 257 & 463 \\
\hline & Chloroplasts & 316 & 439 & 2419 & 677 \\
\hline & Phototrophy & 84 & 131 & 15 & 16 \\
\hline \multirow[t]{4}{*}{ Other } & Dark hydrogen oxidation & 179 & 313 & 428 & 11 \\
\hline & Iron respiration & 0 & 0 & 33 & 0 \\
\hline & Chlorate reducers & 26 & 31 & 7 & 0 \\
\hline & Chemoheterotrophy & 36836 & 42122 & 33798 & 15028 \\
\hline
\end{tabular}


To elucidate the response mechanism of the bacterial community to the addition of carbon sources and nutrients, the possibility of inferring microbial functions based on 16S rRNA sequences was provided by PICRUSt, which used a COG (orthologous group cluster) classification scheme to explore the possibility of collecting bacteria to develop adaptive metabolic functions. As shown in Fig. 6, the abundance of some COGs related to metal detoxification and organic degradation, such as transcriptional regulators (COG0583, COG1309, COG1846, COG2204) and dehydrogenase (COG1012, COG1028), was high. The abundance of COGs in the control group was higher than that in the other treatments or was essentially the same, except for COG0583. Hydrolases are known to be beneficial to the degradation of organic matter, while dehydrogenases (such as oxidoreductase) may be involved in the oxidation of $\mathrm{S}^{-}$(Zhang et al., 2019).

Procrustes was used to characterize the potential consistency of bacterial species abundance, composition, and functional gene abundance composition based on COG functional annotation and genus species classification via PCA, the results of which are shown in Figure 7. The square deviation sum of Procrustes analysis was 0.1479 , indicating a strong correlation between bacterial species abundance and functional gene abundance. At the same time, the similarity of Tx-1 and Tx-2 was highest, followed by Tx-3, and the similarity of functional gene abundance among the three treatments was higher than that of species abundance. Among the treatment groups, compared with that of the control group, the similarity in species abundance and functional gene abundance for these three treatment groups was the lowest.

In previous studies, the catalytic oxidation of oxidizing bacteria such as Thiobacillus ferrooxidans and Thiobacillus thiooxidans was considered an important cause of coal gangue acidification. Sasaki et al. (1998) showed that Thiobacillus ferrooxidans could significantly accelerate pyrite oxidation. Zhong et al. (1987) found that the iron release rate of inoculated pyrite samples was 60 times higher than that of uninoculated samples. However, the results of the present experiment show that the initial stage (0-28 d) of the stacking of the new coal gangue is the critical period for the $\mathrm{pH}$ decrease of the leachate and the main time period for the acidification of coal gangue. On the 28th day of the experiment, the bacterial community on the surface of the coal gangue samples was analyzed by 16S rRNA high-throughput sequencing. Thiobacillus was not the dominant genus in the bacterial community during this period, and the ferrous oxidation rate of the coal gangue leachate was only $9.91 \%$, indicating that the microbial catalysis of ferrous oxidation by Thiobacillus was not obvious. These findings may imply that other factors may affect the acidification of coal gangue.

In the process of coal gangue acidification, a continuous decrease in $\mathrm{pH}$ leads to changes in the microbial community composition and function on the surface of coal gangue. With decreasing $\mathrm{pH}$, the activity of some acidophilic bacteria (such as Thiobacillus) increases (Belzile et al., 1997), but these bacteria usually do not constitute the dominant genera at the beginning of the oxidation process of coal gangue. Therefore, Thiobacillus microorganisms were present only after the gangue had been oxidized for a period of time, which means that the dominance of Thiobacillus in the bacterial community may indicate that the oxidation process of coal gangue had entered the accelerated cycling stage. In another study, we evaluated the microbial community and composition during different periods of coal gangue oxidation. 
The results showed that Thiobacillus usually emerged and rapidly became the dominant genus after the gangue was exposed to air for approximately $50 \mathrm{~d}$. This result may help us better understand the acidification mechanism of coal gangue under open-air conditions. Although attributing the initial acidification of coal gangue to ferrous ion oxidation promoted by Thiobacillus bacteria may not be completely accurate, it is still feasible to reduce the oxidation rate of coal gangue by inhibiting the activity of Thiobacillus bacteria, which prevents the oxidation process of coal gangue from entering the accelerated cycling stage (Hu et al., 2020).

Adding carbon sources and nutrient salts to coal gangue improved the bacterial community structure within the coal gangue, especially the dominance of sulfur-metabolizing bacteria, thus effectively inhibiting the production of acidic mine wastewater. Moreover, the addition of a carbon source effectively increased the number of microorganisms. However, the experimental results showed that the addition of sodium lactate and nutrient salts did not increase the diversity index of the bacterial community on the gangue surface but altered the relative abundance and dominance of different species of bacteria, prompting several functional bacteria (such as Arthrobacter and Enterococcus) to occupy a greater dominant position. However, bacterial growth rapidly consumed the carbon source. When the carbon source supply is stopped, the gangue was acidified quickly. Adding OM in the form of spraying a solution causes a large amount of solute to be lost with water, and only a small proportion of OM can be adsorbed onto the surface of the coal gangue, which makes it difficult to meet the needs of microbial growth. Solid organic waste such as peat, bagasse, and animal manure may be better choices for carbon sources; these sources could not only be implemented into new methods for waste disposal but also reduce environmental pollution caused by coal gangue acidification.

\section{Declarations}

Ethics approval and consent to participate: Not applicable.

Consent for publication: Not applicable.

Availability of data and materials: Not applicable.

Competing interests: The authors declare that they have no competing interests.

Funding: This work was supported by the National Key Research and Development Program (grant number 2019YFC1805003).

Authors' contributions: Conceptualization, ZH and QZ; methodology, MR.; software, MR.; validation, QZ and CY; data curation, QZ and CY; writing-original draft preparation, QZ; writing-review and editing, ZH and $\mathrm{CY}$; supervision, $\mathrm{ZH}$; All authors have read and agreed to the published version of the manuscript.

\section{References}


1. Acharya B.S., Kharel G., 2020. Acid mine drainage from coal mining in the United State: an overview. Journal of Hydrology, 588, 125061.

2. Adil A, Tang H L. 2018. Field investigations of passive and active processes for acid mine drainage treatment: are anions a concern. Ecological Engineering, 122, 100-106.

3. Akcil, A., Koldas, S., 2006. Acid mine drainage (AMD): Cause, treatment, and case studies. J. Cleaner Prod. 14, 1139-1145.

4. Aller A, Martlnez O, Linaje J A, et al. 2001. Biodesulphurisation of coal by microorganisms isolated from the coal itself. Fuel Processing Technology, 69, 45-57.

5. Arora PK, Jain RK., 2011. Pathway for degradation of 2-chloro-4-nitrophenol in Arthrobacter sp.. Current Microbiology, 63, 568-573.

6. Baker, B.J., Banfield, J.F., 2003. Microbial communities in acid mine drainage. FEMS Microbiol. Ecol. 44, 139-152.

7. Barton L.L., Fauque G.D., 2009. Biochemistry, physiology and biotechnology of sulfate-reducing bacteria. Advances in Applied Microbiology, 68, 41-98.

8. Belzile N., Maki S., Chen Y.W., et al., 1997. Inhibition of pyrite oxidation by surface treatment. Science of the Total Environment, 196, 177-186.

9. Bozau E., Bechstedt T., Friese K., 2006. Biotechnological remediation of an acidic pit lake: Modelling the basic processes in a mesocosm experiment. Journal of Geochemical Exploration, 92, 212-221.

10. Cai T.M., Chen L.W., Ren Q., et al., 2011. The biodegradation pathway of triethylamine and its biodegradation by immobilized Arthrobacter protophormiae cells. Journal of Hazardous Materials, 186, 59-66.

11. Chee-Sanford J., Tian D., Sanford R., 2019. Consumption of $\mathrm{N}_{2} \mathrm{O}$ and other $\mathrm{N}$-cycle intermediates by Gemmatimonas aurantiaca strain T-27. Microbiology, 165

12. Chen J., Liu Y., Diep P., et al., 2021, Genomic analysis of a newly isolated Acidithiobacillus ferridurans JAGS strain reveals its adaptation to acid mine drainage. Minerals. 11, 74.

13. Egiebor, N.O.; Oni, B. 2007. Acid rock drainage formation and treatment: A review. Asia Pac. J. Chem. Eng. 2, 47-62.

14. Geldenhuis S., Bell F.G., 1998. Acid mine drainage at a coal mine in the eastern Transvaal, South Africa. Environmental Geology, 34, 234-242.

15. Hou H.P., Wang C., Li J.R., et al., 2017. Variation of bacterial community structure and enzyme activities in reclaimed soil filled with coal gangues along a reclamation chrono sequence. 37,4230 4240.

16. Hu ZQ, Yang, XH, Bao Y, et al. 2005. On the restoration of mine Eco-environment. Science \& Technology Review. 23, 38-41.

17. Hu, Z.Q., Ma, B.G., Zhang, M.L., et al., 2009. Bioremediation of sulfuric contamination from coal wastes by sulfate-reducing bacteria (SRB). J. China Coal Soc. 34, 400-404. 
18. Hu Z.Q., Zhu Q., Xu J.J., et al., 2020. Effect of Bactericides on Control of Acidification Pollution and Spontaneous Combustion of Coal Gangue Dumps in China and Its Mechanism. Sustainability, 12.

19. Jacobs J A, Lehr J H, Testa S M. 2014. Acid Mine Drainage, Rock Drainage, and Acid Sulfate Soils: Causes, Assessment, Prediction, Prevention, and Remediation. John Wiley \& Sons, Inc.

20. Jin S, Fallgren P H, Morris J M, et al., 2008. Biological source treatment of acid mine drainage using microbial and substrate amendments: microcosm studies. Mine Water and the Environment, 27, 2030.

21. Jin S., Fallgren P.H., Morris J.M., et al., 2008. Source treatment of acid mine drainage at a backfilled coal mine using remote sensing and biogeochemistry. Water, air, and soil pollution, 188, 205-212.

22. Jing Q, Zhang M, Liu X, et al. 2017. Bench-scale microbial remediation of the model acid mine drainage: Effects of nutrients and microbes on the source bioremediation. International Biodeterioration \& Biodegradation, 128: 117-121

23. Kim S.D., Kilbane J.J., Cha D.K., 1999. Prevention of acid mine drainage by sulfate reducing bacteria: organic substrate addition to mine waste piles. Environmental Engineering Science, 16, 139-145.

24. Knöller K, Fauville A, Mayer B, et al. 2004. Sulfur cycling in an acid mining lake and its vicinity in Lusatia, Germany. Chemical Geology, 204, 303-323.

25. Leathen,W.W., Braley, S.A., Mcintyre, L.D. 1953. The Role of Bacteria in the Formation of Acid from Certain Sulfuritic Constituents Associated with Bituminous Coal. Appl. Microbiol. 1, 61-68.

26. Li J., Constantine U., Leng Y., et al., 2017. Progress on the study of biodegradation of organic pollutants and adsorption of heavy metals with Arthrobacter strains. Environmental Science \& Technology, 40, 89-97.

27. Li J.R., Hou H.P., Wang C., et al. 2018. Soil bacteria diversity of reclaimed soil based on high throughput sequencing. Environmental Science \& Technology, 41, 148-157.

28. Liao J.Q., Guo X.D., Weller D.L., et al., 2021. Nationwide genomic atlas of soil-dwelling Listeria reveals effects of selection and population ecology on pangenome evolution. Nature Microbiology. 6, 10211030.

29. Ma B.G., Hu Z.Q.,2014. Simulation experiment on control of coal gangue pollution using sewagesludge and fly ash covering. Journal of Agro-Environment Science. 33, 1553-1559

30. Marris E., 2006. Putting the carbon back: Black is the new green. Nature, $442,624-626$.

31. Naidu G, Ryu S, Thiruvenkatachari R, et al., 2019. A critical review on remediation, reuse, and resource recovery from acid mine drainage. Environmental Pollution, 247, 1110-1124.

32. Phyo A K, Jia Y, Tan Q, et al., 2020. Competitive growth of sulfate-reducing bacteria with bioleaching acidophiles for bioremediation of heap bioleaching residue. International Journal of Environmental Research \& Public Health, 17, 2715.

33. Prasad K.S., Ramanathan A.L., Paul J, et al., 2013. Biosorption of arsenite $\left(\mathrm{As}^{3+}\right)$ and arsenate $\left(\mathrm{As}^{5+}\right)$ from aqueous solution by Arthrobacter sp. biomass. Environmental Technology, 34, 2701-2708. 
34. Sasaki K, Tsunekawa M., Ohtsuka T., et al., 1998. The role of sulfur Thiobacillus thiooxidans in pyrite weathering. Colloids and Surfaces A: Physicochemical and Engineering Aspects. 133, 269-278.

35. Senoro D B, Bonifacio P B, Mascareas D R, et al. 2021. Spatial distribution of agricultural yields with elevated metal concentration of the island exposed to acid mine drainage. Journal of Degraded and Mining Lands Management, 8, 2551-2558.

36. Skousen J G, Ziemkiewicz P F, Mcdonald L M. 2019. Acid mine drainage formation, control and treatment: approaches and strategies. The Extractive Industries and Society, 6, 241-249.

37. Sebai TE, Devers-Lamrani M., Changey F., et al., 2011. Evidence of atrazine mineralization in a soil from the nile delta: isolation of Arthrobacter sp. TES6, an atrazine-degrading strain. International Biodeterioration and Biodegradation, 65, 1249-1255.

38. Slaska, Metalurgii K, Katowice, et al., 2003. Microbial leaching of blende flotation concentrate using Acidithiobacillus ferrooxidans and Acidithiobacillus thiooxidans. Physico chemical Problems of Mineral Processing, 37, 57-68

39. Song L.C., Niu X.G., Zhang N.W., et al., 2021. Effect of biochar-immobilized Sphingomonas sp. PJ2 on bioremediation of PAHs and bacterial community composition in saline soil. Chemosphere, 279,130427

40. Su X., Luo H., Yue Z.H., et al., 2020. Effects of carbon addition on community structure diversity of $\mathrm{CO}_{2}$-assimilating bacterial in Saline-alkali cultivated land. China Environmental Science. 40, 44964503.

41. Tang, J.L., He, H., Zhang, W.J., et al., 2014. Isolation and identification of SRB and its utilization on processing of acid mine drainage of coal gangue dump. J. China Coal Soc. 39, 2307-2314.

42. Tuttle J H, Dugan P R, Randles C I., 1969. Microbial Sulfate Reduction and Its Potential Utility as an Acid Mine Water Pollution Abatement Procedure. Applied microbiology, 17(2):297-302.

43. Wang X, Di J, Dong Y, et al. 2021. The dynamic experiment on treating acid mine drainage with iron scrap and sulfate reducing bacteria using biomass materials as carbon source. Journal of Renewable Materials, 9, 163-177.

44. Wang Y, Wang C, Li A, et al., 2015. Biodegradation of pentachloronitrobenzene by Arthrobacter nicotianae DH19. Letters in Applied Microbiology, 61, 403-410.

45. Yao S., Sheng L.X., Wang Z.Q., et al., 2016. Responses of soil enzyme activity and microbial community compositions to nitrogen addition in bulk and microaggregate soil in the temperate steppe of Inner Mongolia. Eurasian Soil Science, 49, 1149-1160

46. Ye S.H., Zhang M.P., Yang H., et al., 2014. Biosorption of $\mathrm{Cu}^{2+}, \mathrm{Pb}^{2+}$ and $\mathrm{Cr}^{6+}$ by a novel exopolysaccharide from Arthrobacter sp-5. Carbohydrate Polymers, 101, 50-56.

47. Yoon J.H., Kim S.A., Shim W.B., et al., 2021. Colonization of Listeria monocytogenes in potting soils as affected by bacterial community composition, storage temperature, and natural amendment. Food Science and Biotechnology. 30, 869-880.

48. Zhang C., Zhou T.T., Zhu L.S., et al., 2019. Response of soil microbes after direct contact with pyraclostrobin in fluvo-aquic soil. Environmental Pollution, 255, 113164 
49. Zhong H.F., Cai W.L., Li Y.Q., 1987. Bacterial Oxidation of Pyrite. Acta Microbiol. Sin. 27, 264-270.

50. Zhou X.Y., Hou H.P., Liu H.Y., et al., 2020. Study on variation characteristics of soil microbial community system in different reclamation years: taking Jiawang mining area in Xuzhou as an example. Environmental Science \& Technology, 43, 219-228.

51. Zhu Q., Hu Z.Q., Ruan M.Y., 2020. Characteristics of sulfate-reducing bacteria and organic bactericides and their potential to mitigate pollution caused by coal gangue acidification. Environmental Technology \& Innovation, 20, 101142

\section{Figures}
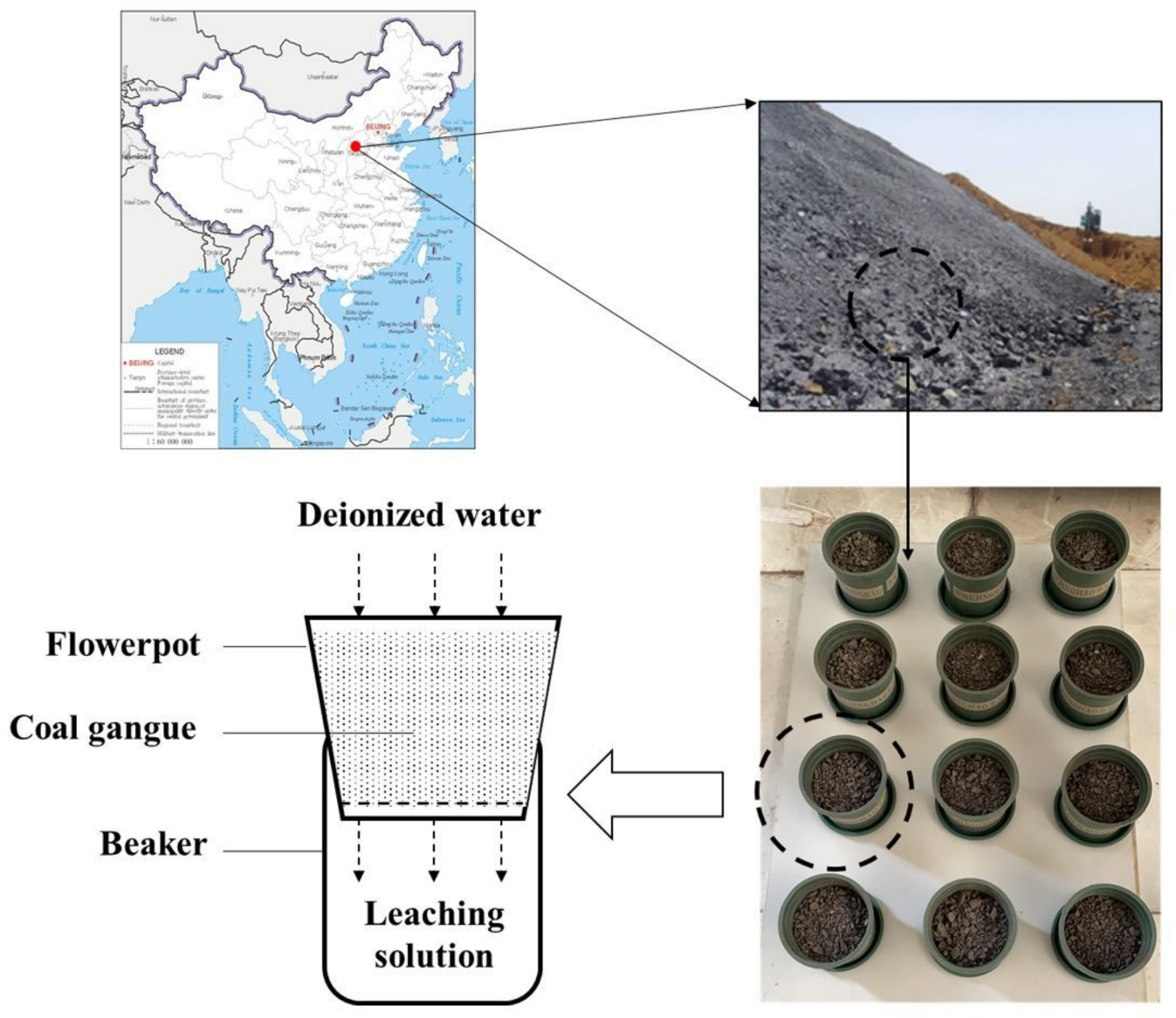

Figure 1 
Experimental steps and schematic diagram of the device

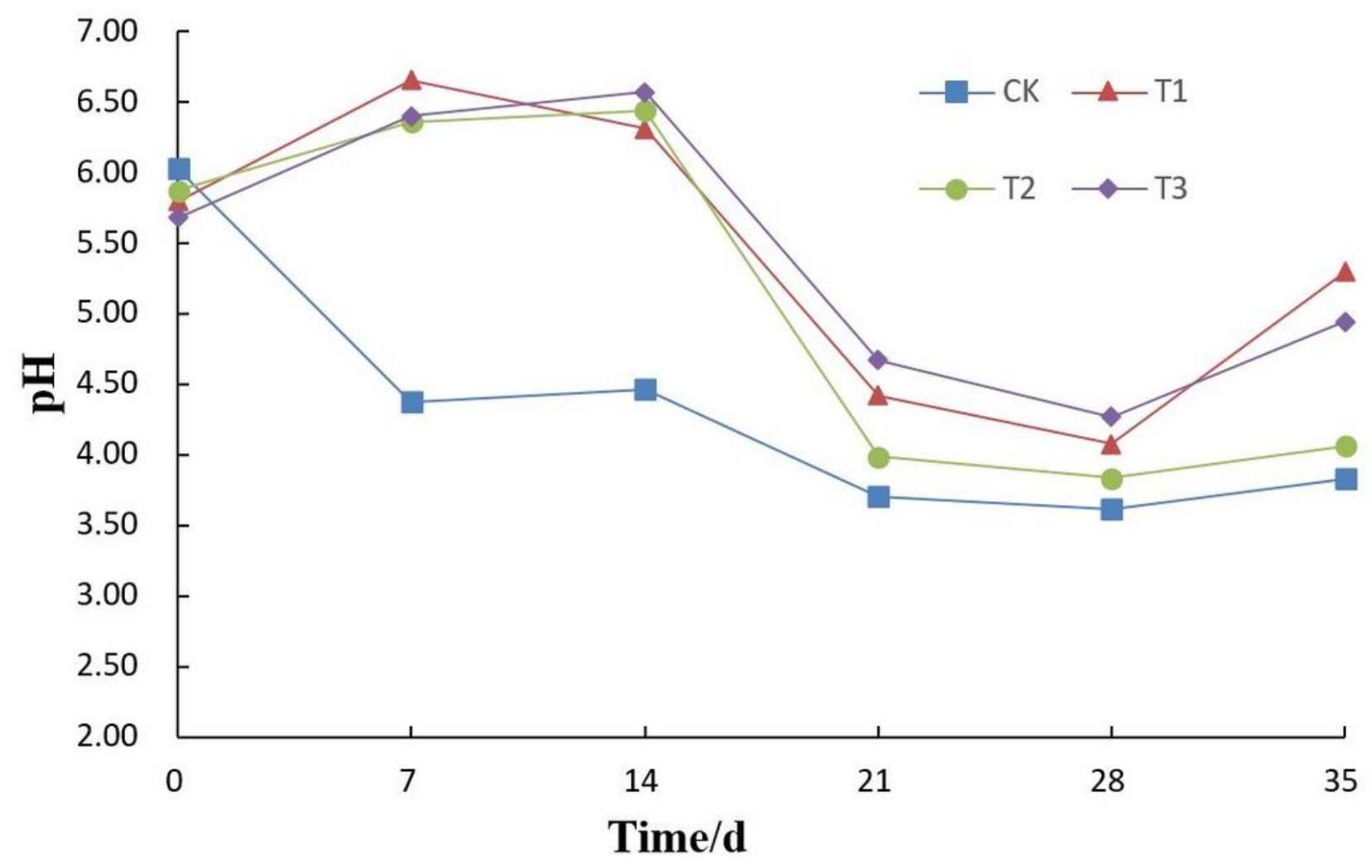

Figure 2

$\mathrm{pH}$-time curve of the coal gangue leachate 


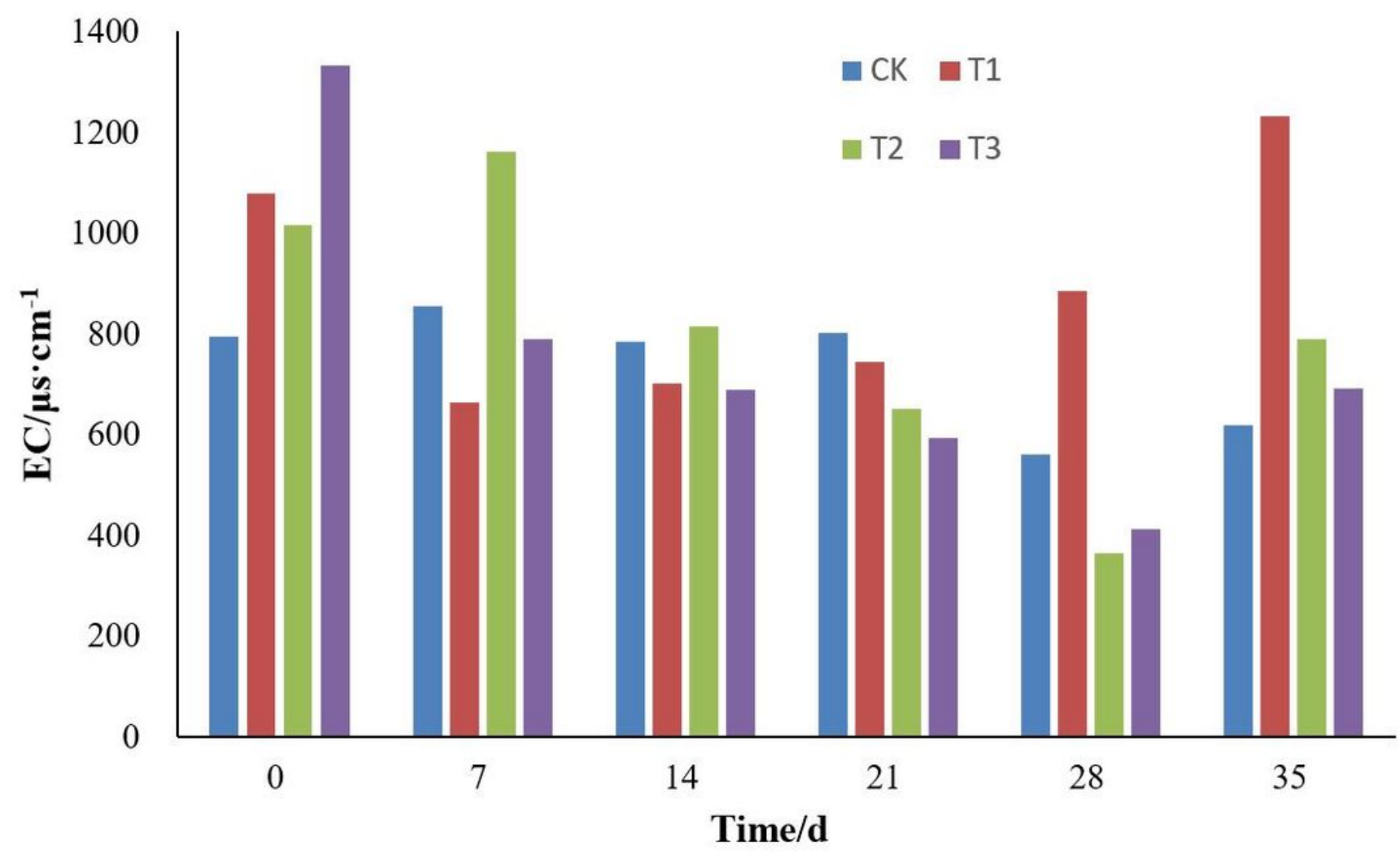

Figure 3

Changes in EC of coal gangue leachate under different treatments 


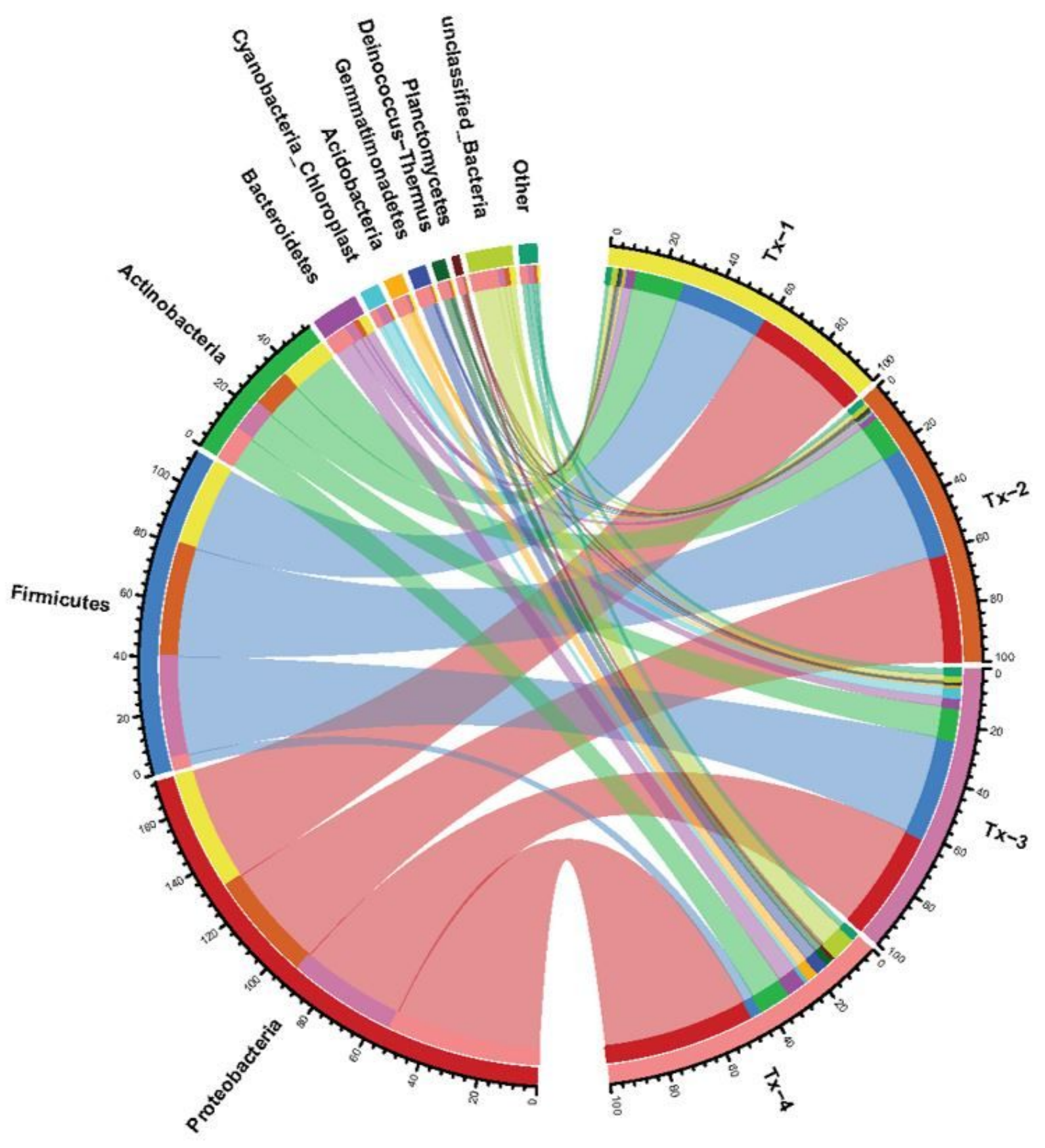

Figure 4

Collinearity diagram (phylum level) 


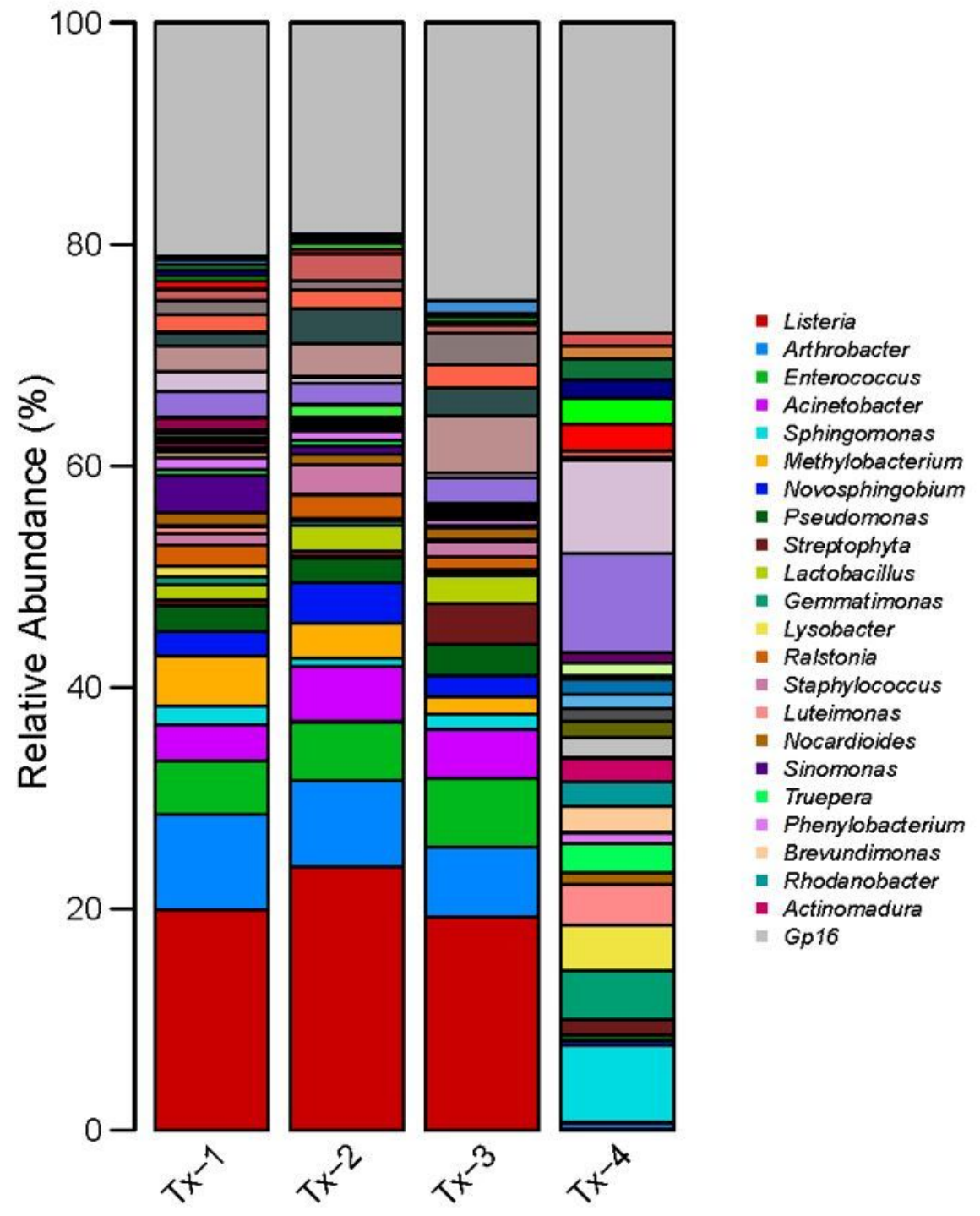
- Porphyrobacter
- Thermomonas
- Leifsonia
- Aequorivita
- Terrabacter
- Escherichia_Shigella Vulcanibacillus
- Azoarcus
- unclassified Bacteria
- unclassified_Xanthomonadaceae
- unclassified Burkholderiales
- unclassified_Firmicutes
- unclassified Brucellaceae
- unclassified_Enterobacteriaceae
- unclassified_Oxalobacteraceae
- unclassified_Betaproteobacteria
- unclassified Rhizobiales
- unclassified_Chr̈inophagaceae
- unclassified Alphaproteobacteria
- unclassified_Methylophilaceae
- unclassified Sinobacteraceae
- unclassified Clostridiaceae 2
= Other

Figure 5

Relative abundance of bacteria in the coal gangue (genus level) 


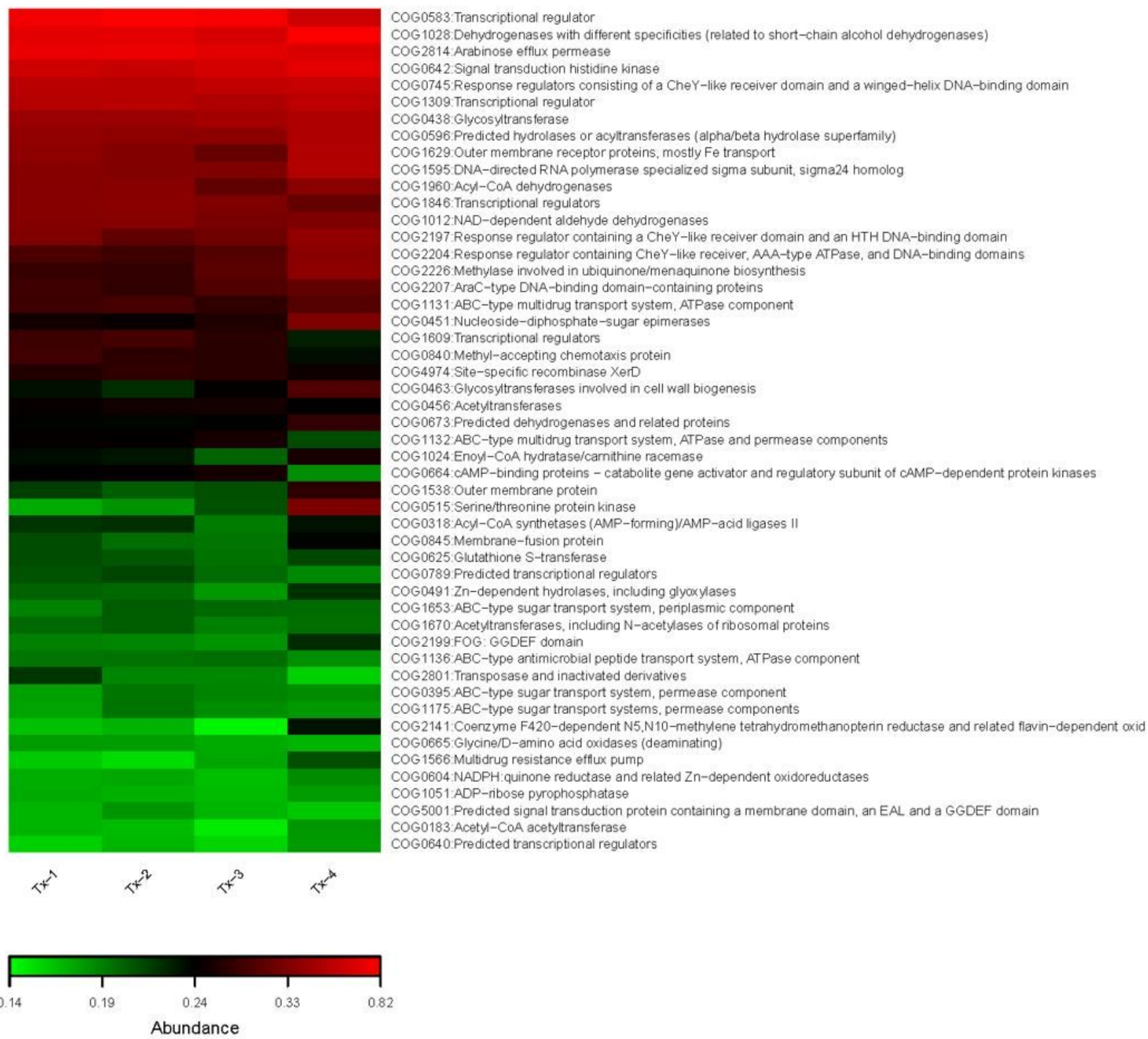

\section{Figure 6}

\section{Heat map of the predicted functions of genes within the bacterial community}




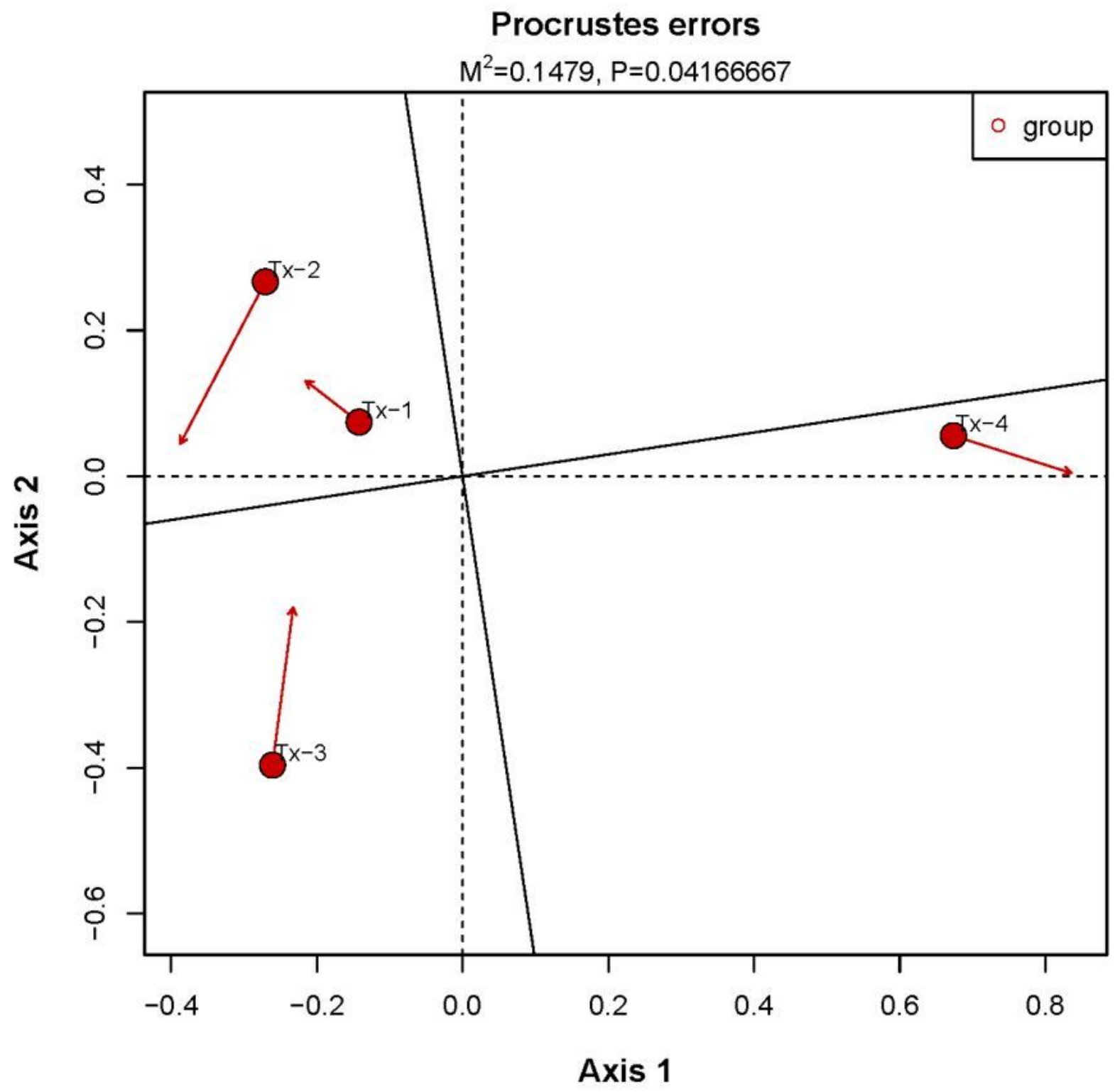

Figure 7

Abundance of functional genes within the bacterial community according to PCA 